\title{
Factors influencing HIV testing uptake among priority populations in a resettlement colony of a North Indian city
}

Ishita Choudhary ${ }^{1}$, Venkatesan Chakrapani ${ }^{2}$, Manmeet Kaur ${ }^{3}$, Sandeep Mittal ${ }^{4}$, Rajesh Kumar ${ }^{5}$

${ }^{1}$ Masters of Public Health, School of Public Health, Post Graduate Institute of Medical Education and Research (PGIMER), Chandigarh; ${ }^{2}$ Chairperson, Centre for Sexuality and Health Research and Policy (C-SHaRP), Chennai \& Wellcome Trust / DBT India Senior Fellow, The Humsafar Trust, Mumbai; ${ }^{3}$ Professor, School of Public Health, Post Graduate Institute of Medical Education and Research (PGIMER), Chandigarh; ${ }^{4}$ Deputy Director (TI), Chandigarh State AIDS Control Society, Chandigarh; ${ }^{5}$ Professor and Head, School of Public Health and Dean (Academic), Post Graduate Institute of Medical Education and Research (PGIMER), Chandigarh

\begin{tabular}{|c|c|c|c|c|c|c|c|c|}
\hline Abstract & Introduction & Methodology & Results & Conclusion & References & Citation & \multicolumn{2}{|c|}{ Tables / Figures } \\
\hline \multicolumn{9}{|c|}{ Corresponding Author } \\
\hline \multicolumn{8}{|c|}{$\begin{array}{l}\text { Dr. Rajesh Kumar, School of Public Health, Post Graduate Institute of Medical Education and Research } \\
\text { (PGIMER), Chandigarh } \\
\text { E Mail ID: dr.rajeshkumar@gmail.com }\end{array}$} & 口is \\
\hline
\end{tabular}

\section{Citation}

Choudhary I, Chakrapani V, Kaur M, Mittal S, Kumar R. Factors influencing HIV testing uptake among priority populations in a resettlement colony of a North Indian city. Indian J Comm Health. 2020;32(1):31 - 38.

Source of Funding: Nil Conflict of Interest: None declared

\section{Article Cycle}

Received: 19/11/2019; Revision: 07/01/2020; Accepted: 20/02/2020; Published: 31/03/2020

This work is licensed under a Creative Commons Attribution 4.0 International License.

\section{Abstract}

Background: The recent adoption of HIV 'test and treat' strategy by India's National AIDS Control Organization (NACO) necessitates an urgent need to improve HIV testing among priority populations at risk for HIV. Aim \& Objectives: To identify barriers to and facilitators of HIV testing among priority populations such as pregnant women, tuberculosis patients, sexual partners of people living with HIV (PLHIV) and key populations; and to examine the role of new HIV testing modalities (e.g., non-invasive HIV testing) in improving HIV testing. Settings and Design: A cross sectional survey was conducted among priority populations in a resettlement colony of Chandigarh, North India. Materials and methods: A total of 160 participants were recruited using non-probability-based sampling. Statistical analysis used: Chi-square test was used to assess differences between priority populations who had been tested or not tested for HIV. Multivariable logistic regression was conducted to identify significant predictors of HIV testing status. Results: Participants with higher HIV knowledge (Adjusted Odds Ratio [aOR] $=1.7,95 \% \mathrm{Cl} 1.2$ to 2.5 ) and family support (aOR=8.2, 95\% Cl 1.9 to 35.3 ) had higher odds of getting tested for HIV. Major barriers identified were fear of anticipated discrimination and previous bad experiences in government HIV testing centres, and key facilitators were empathetic attitude of the staff and government initiatives (e.g., free-of-cost tests, reimbursements of travel costs). For periodic testing, priority populations preferred non-invasive (non-blood-based) HIV tests. Conclusions: Interventions to promote HIV testing among priority populations need to reduce HIV-related stigma, and offer non-invasive HIV testing in public hospitals.

\section{Keywords}

Odds Ratio; Cross-Sectional Studies; Sexual Partners; Logistic Models; HIV; Social Stigma; Mass Screening

\section{Introduction}

Globally, HIV prevalence among adults was estimated to be $0.8 \%$ in $2017 .(1)$ In India, while the HIV prevalence among general population is low (0.22\% in 2017), it is relatively high among key populations at risk for HIV (e.g., among Transgender Women or TGW - 7.5\% and Injecting Drug Users or IDUs - 9.9\%).(2) Although there was a $66 \%$ decline in new HIV infections in India from 2000 to $2015,(2) \quad 28 \%$ of PLHIV do not know their HIV status.(3)
India is among the thirty-five 'Fast-Track countries' with more than $90 \%$ of the people becoming newly infected with HIV and require intensified action to achieve WHO's 90-90-90 targets.(4) To reach the first 90 target (90\% of PLHIV should be aware of their status), an additional 7.5 million people need to access HIV testing services in India,(1) a major gap.

Recently, India's National AIDS Control Organization identified several priority populations (e.g., pregnant/breastfeeding women, and key populations) 
among whom HIV testing uptake need to be improved.(5)

Therefore, a study was conducted among priority populations in a resettlement colony of Chandigarh to identify the barriers to and facilitators of HIV testing and to examine the role of new HIV testing modalities in improving HIV testing.

\section{Aims \& Objectives}

Primary Objective: To identify barriers to and facilitators of HIV testing among priority populations at risk for HIV.

Secondary Objective: To examine the role of new HIV testing modalities in improving HIV testing.

\section{Material \& Methods}

\section{Study setting and design}

A cross-sectional study was conducted among priority populations in a resettlement colony of Chandigarh, India. The sample included men and women from priority populations such as pregnant women, tuberculosis patients, sexual partners of PLHIV and key populations such as female sex worker (FSWs), men having sex with men (MSM), injecting drug users (IDUs) and transgender women (TGW). A common inclusion criterion for all groups was their age should be 18 years or above. Specific inclusion criteria for certain priority populations were: for pregnant women - those in the second or third trimester of pregnancy; and for TB patients - those on Directly Observed Treatment - Short course (DOTS) for more than 2 months.

\section{Sample size and sampling technique}

At a significance level of 0.05 , and prevalence of barriers and facilitators at $50 \%$, a sample size of at least 96 was estimated. Considering a design effect of 1.5 and $10 \%$ refusals, the final sample size was estimated to be 158 (rounded off to 160) for the study. Non-probability-based sampling (Quota sampling) was used because of the lack of a sampling frame for probability-based sampling for most of the priority populations, and it allowed to sample subgroups that were of great interest to the study. Among each of the four key population groups (FSWs, MSM, IDUs and TGW), a sample size of 10 was chosen.

\section{Data collection}

A structured questionnaire collected information on socio-demographic details (age, gender, education, income, and marital status), awareness and knowledge about HIV and Integrated Counselling and Testing Centre (ICTC) services, HIV testing uptake, and factors that may influence testing uptake (e.g., family support, confidentiality at the testing centre, distance of the testing centre from home). A few open-ended questions were included as well to enquire about other barriers/facilitators not listed in the questionnaire and to obtain the views of participants on how to improve HIV testing uptake.

\section{Statistical analysis}

SPSS statistics 17.0 (SPSS Inc., Chicago, IL, USA) was used for data analysis. Descriptive statistics was used to present socio-demographic profile, HIV/AIDS knowledge, selfperception of HIV risk and exposure to HIV programmes. Chi-square test was used for bivariate analysis to assess differences among proportions among priority populations who had been tested or not tested for HIV. Multivariable logistic regression was conducted to find out significant predictors of HIV testing status.

\section{Ethics approval}

The ethical clearance for the study was taken from the Institutional Ethics Committee of Post-Graduate Institute of Medical Education and Research (PGIMER), Chandigarh (NK/3420/MPH/932). Written informed consent was obtained from all the participants.

\section{Results}

A total of 160 participants were enrolled in the study, with $57 \%$ of women, $36 \%$ of men and $7 \%$ of TGW. The median age of the study participants was 28 years (interquartile range 12.7 years). About two-third (70\%) were educated up to 12 th grade. Nearly three-quarter $(76 \%)$ were living in urban area (Table 1).

Among the priority populations, key populations had highest knowledge on HIV prevention (98\%), followed by sexual partners of PLHIV (95\%), pregnant women (65\%) and TB patients (50\%).

HIV testing uptake, and its association with sociodemographic and behavioral factors

Of the 160 participants enrolled, 146 (91\%) had ever been tested for HIV. Testing uptake was highest among men (97\%). HIV testing uptake was lowest among participants who had no formal education (78\%). For participants living in urban areas, HIV testing uptake was $89 \%$. Significant association with HIV testing uptake was found for age, educational status, and residence. Out of the 146 participants who had tested for HIV, all of those who belonged to the age group of 31-45 years had undergone HIV testing (100\%), followed by those above 45 years (95\%) and those between 18 and 30 years (87\%) (Table 2). Among participants who received support from family and who were in contact with service providers (peer educator/healthcare provider), 98\% and 93\%, respectively, had been tested for HIV. Using multivariable logistic regression, significant predictors of HIV testing status were found. Participants with higher HIV knowledge (Adjusted Odds ratio [aOR]=1.7, 95\% Cl 1.2 to 2.5) and family support ( $\mathrm{aOR}=8.2,95 \% \mathrm{Cl} 1.9$ to 35.3) had higher odds of getting tested for HIV (Table 3 ).

\section{Barriers and Facilitators to HIV testing uptake}

Anticipated discrimination was high among sexual partners of PLHIV (54\%) followed by key populations (15\%), TB patients (6\%) and pregnant women (3\%). Preference for the nearby facility for HIV testing was mainly reported by pregnant women (83\%), key populations ( $80 \%$ ) and TB patients (75\%). Reported lack of confidentiality was low among sexual partners of PLHIV (5\%) and key populations (10\%). 
Half (50\%) of the key populations reported having been treated unfairly by family, friends or neighbors. Twentyeight percent of key populations reported discrimination at the health facilities and nearly one-third (33\%) reported having received low quality of services at health facilities. Harassment by police was reported by $43 \%$ of key populations.

Overall, majority of the facilitators were observed among sexual partners of PLHIV and key populations. Enrolment with non-governmental organizations (NGOs) implementing HIV projects was considered the most important facilitator for HIV testing among key populations and sexual partners of PLHIV (98\%). Government initiatives (such as provision of free-of-cost tests, monetary reimbursements of travel cost, large scale advertisements and collaboration with private facilities to offer free HIV tests) motivated $88 \%$ of TB patients, $80 \%$ of key populations, $78 \%$ of sexual partners of PLHIV and $75 \%$ of pregnant women. Knowing an HIV-positive person was a major facilitator of HIV testing among key populations (98\%).(Figure 1) \& (Figure 2)

A range of barriers and facilitators for HIV testing from the open-ended responses were identified and categorized as structural/policy level, societal level, health care system level and personal and interpersonal level, based on the social-ecological framework (Table 4). Personal and interpersonal level facilitators of HIV testing were primarily reported among all key populations and 93\% of sexual partners of PLHIV. Among key populations, personal/interpersonal level barriers, and health care system level barriers were $48 \%$ and $40 \%$, respectively.

\section{Role of newer HIV testing modalities}

Majority preferred government facilities for HIV testing. For example, $98 \%$ of TB patients and sexual partners of PLHIV and $85 \%$ of pregnant women preferred government facilities. The mobile van testing facility was used by only key populations (40\%). Out of 135 participants who were willing to access government hospitals for HIV testing, 9\% reported never having been tested whereas all those participants who were willing to test at mobile van testing had undergone HIV testing. About two-fifth (41\%) of participants and $58 \%$ of key populations were willing to use non-invasive (saliva/urine) HIV testing method (Table 5).

\section{Discussion}

The recent scale-up of HIV testing and treatment strategies across the country aims to end HIV transmission by 2030.(6) However, as reported earlier, given that the national response faces institutional constraints, both structural and managerial,(6) priority populations in Chandigarh were also found to be facing barriers and facilitators to HIV testing uptake at multiple levels, despite free testing programs at government facilities.

\section{Barriers to HIV testing}

[Factors influencing HIV...] | Choudhary I et al

At the structural/policy level, inadequacy of funds was a key barrier to HIV testing uptake. Participants working in NGOs that implemented HIV programs had reported shortage of human resources along with perceived low salary packages. They had also reported delays in receiving their salaries that demotivated them to work efficiently and encourage HIV testing among other priority populations. These findings were similar to those reported in a study (7) in which policies that prevent employment of peer counsellors contributed to barriers to HIV testing among key populations.

Societal level barriers like stigma and discrimination have been previously shown to have a profound impact on HIV testing among key populations. $(7,8,9)$ The fear of discrimination was coupled with fear of relationship discord among friends/family or even clients. Among key populations, the anticipated fear of rejection from their own community, eviction from home, social isolation and loss of income from the sex work negatively influenced the HIV testing uptake. These barriers identified in this study were consistent with previous research that related stigma and discrimination to fear of rejection. $(7,8,9,10,11)$

At the health care system level, this study found that all priority populations reported these barriers: perceived insensitivity of health care providers, previous bad experiences at the health facilities and inconsiderate administrative norms in testing facilities. Incidents of discrimination were reported by IDUs and TGW in public health settings. These findings are consistent with other studies $(7,8,9)$ where mistreatment by health care providers and lack of culturally-appropriate services were shown to discourage HIV testing uptake among key populations.

At the personal level, lack of knowledge about HIV/AIDS was related to fear of death. Consistent with other research, $(8,12)$ this study found that those with higher HIV knowledge are more likely to have been tested for HIV. Similarly, concerns about partner's reaction to one's HIV positive status identified in this study was consistent with a South African research (11) that found HIV testing to be delayed due to fear of potential conflict with partner. Low self-risk perception of HIV and fear of HIVpositive result were found to be linked to fears of adverse consequences of HIV disclosure. $(7,8,9,11,12,13)$ The present study has also shown that less than one-fourth of the participants perceived themselves at risk of HIV infection.

In this study, FSWs and pregnant women had mentioned distance as a barrier to HIV testing. This was due to the travel cost involved in it. Among IDUs providing incentives, monetary reimbursements of travel cost or arrangements of refreshment at testing facilities were seen to encourage HIV testing uptake. A South African study also mentioned 
similar findings where lack of incentives or monetary reimbursements had served as a barrier to HIV testing.(11)

\section{Facilitators of HIV testing}

Consistent with other studies, $(8,9)$ this study found support of family as a significant facilitator of HIV testing among all priority populations. Peer educators (service providers) are often the key source of information about HIV to key populations, and considered more trustworthy and reliable than someone outside the community. Peerled programme can expand the coverage among key populations as supported by a study conducted in NorthEastern India among IDUs. (14) Although all key populations were found to be in contact with peer educators, HIV testing uptake was still suboptimal, indicating the role of other factors. Consistent with other studies, $(8,11,13)$ empathetic staff behavior (providing respect and confidentiality) was reported to have increased HIV testing across all the groups.

The role of new HIV testing modalities in improving HIV testing uptake

When enquired about the preference in the modality of HIV testing for, none of the participants were aware about non-invasive testing methods (saliva/urine). But after a brief explanation, more than half of the key populations were willing to opt for this newer modality. However, some participants from the other priority populations raised concerns regarding the reliability and efficiency of these methods. Similar to a study from South India, (7) this study also suggests that availability of non-invasive testing methods can expand the reach of HIV testing programmes among key populations.

Currently, non-invasive tests are unavailable in the government testing facilities. In order to scale-up the HIV testing uptake, these methods can be provided as an option in the government health facilities. Furthermore, WHO recommends self-testing for HIV using these methods, where a person collects his or her own specimen (oral fluid or blood) and performs an HIV test and interprets the result, often in a private setting.(14) Selftesting could also partly address the fear of discrimination and stigma among key populations.

This study found that the majority of pregnant women, TB patients and sexual partners of PLHIV preferred government facilities over private facilities to undergo HIV testing. Consistent with other studies, $(15,16)$ half of the key populations preferred mobile van testing as the mobile van comes to their place and there is little waiting period. (Figure 3 )

\section{Conclusion}

Although most of the participants had tested at least once, the participants stated several barriers that hindered first time and repeat HIV testing. These barriers led to delayed HIV testing and subsequently delayed linkage to ART for those who were tested positive. The key barriers identified were fear of discrimination from society, low self-risk perception of HIV, lack of knowledge about HIV/AIDS and previous bad experiences during HIV testing. Key facilitators were supportive role of family and peer educators, empathetic staff attitude in government health facilities and government initiatives like mobile van testing. For periodic testing (HIV testing twice a year recommended by NACO).(17) key populations preferred non-invasive HIV tests. Addressing these barriers could significantly improve HIV testing uptake among priority populations.

\section{Recommendation}

To improve HIV testing uptake among priority populations, actions are needed at several levels. At the health care system level, stigma reduction initiative to reduce discrimination faced by key populations and introduction of non-invasive HIV testing modalities need to be considered. Health care facilities, where possible, should ensure same-day results to make HIV testing experience hassle-free for all populations. At the individual level, improving one's self-assessment related to HIV risk and emphasizing the importance of repeat testing are needed. At the programme level, policies on adoption of newer testing methods like non-invasive tests (urine/saliva) and encouragement of HIV self-testing among at least key populations are needed.

\section{Limitation of the study}

This study has several limitations. First, the sampling technique used was non-probability based; thus, the findings may not be generalizable to priority populations. However, the open-ended component of the questionnaire captured multiple perspectives and experiences. Being a pilot study, the sample size for the subgroups in the study was relatively small. Social desirability bias may have resulted in under-reporting of unfavorable experiences at HIV services or over-reporting of HIV testing uptake. To overcome this bias, survey participants were interviewed confidentially in a private space and assured that their responses will not be revealed to others. The cross-sectional nature of this study prevents the determination of causality. However, open-ended questions in the survey offered details about the nature of barriers and facilitators. Future research should consider using probability-based sampling techniques with adequate sample size of subgroups to provide more robust results.

\section{Relevance of the study}

This study identified multi-level key barriers and facilitators of HIV testing uptake among priority populations at risk for HIV and offer evidence-based suggestions for improving the uptake of first time and repeat HIV testing among these populations in India.

\section{Authors Contribution}

All authors have contributed equally. 


\section{Acknowledgement}

A sincere thanks to Dr. Kanica Kaushal, Senior resident of Community Medicine, School of Public Health, PGIMER, Chandigarh and Mr. Vijin PP, Data analyst, PGIMER, for their support during data collection and analysis.

\section{References}

1. World Health Organization HIV/AIDS. Available at: http://www.who.int/mediacentre/factsheets/fs360/en/. Accessed on Jan 18th, 2019.

2. Government of India. Annual Report 2016-2017, New Delhi, India: National AIDS Control Organization (NACO); 2017. p340.

3. Government of India. National Strategic Plan for HIV/AIDS and STI 2017-2024, New Delhi, India: National AIDS Control Organization (NACO); 2017. p31.

4. World Health Organization. Progress report 2016: Prevent HIV, test and treat all: WHO support for country impact, Geneva, Switzerland: WHO; 2016. p8.

5. Government of India. National HIV Counselling \& Testing Services Guideline, New Delhi, India: National AIDS Control Organization (NACO); 2016. p23.

6. Government of India. National Strategic Plan for HIV/AIDS and STI (2017-2024), New Delhi, India: National AIDS Control Organization (NACO); 2017. p19.

7. Woodford MR, Chakrapani V, Newman PA, Shunmugam M. Barriers and facilitators to voluntary HIV testing uptake among communities at high risk of HIV exposure in Chennai, India. Glob Public Health. 2015;11(3):363-76.

8. Beattie TSH, Bhattacharjee $P$, Suresh M, Isac $S$, Ramesh BM, Moses $S$. Personal, interpersonal and structural challenges to accessing HIV testing, treatment and care services among female sex workers, men who have sex with men and transgender women women in Karnataka state, South India. J Epidemiol Community Health. 2012;66(2):42-8.

9. Chakrapani V, Mittal S, Gupta V, Kumar R. HIV care cascade for priority populations in Chandigarh. Conference Presentation by Chandigarh State AIDS Control Society (AIDSCON). 2016 Feb 27.

10. Chanda MM, Perez-Brumer AG, Ortblad KF, Mwale M, Chongo S, Kamungoma N. Barriers and facilitators to HIV testing among Zambian female sex workers in three transit hubs. AIDS Patient Care STDS. 2017;31(7):291-94.

11. Mohlabane N, Tutshana B, Peltzer K, Mwisongo A. Barriers and facilitators associated with HIV testing uptake in South African health facilities offering HIV Counselling and Testing. Health SA Gesondheid. 2016;21:86-95.

12. Woodford MR, Newman PA, Chakrapani V, Shunmugam M, Kakinami L. Correlates of HIV testing uptake among kothi-identified men who have sex with men in public sex environments in Chennai, India. AIDS Behav. 2012;16(1):53-62.

13. Wet HD, Kagee A. Perceived barriers and facilitators to HIV testing in South African communities. J Health Psychol. 2016;23(12):163545.

14. World Health Organization. HIV Testing Services: WHO recommends HIV Self-Testing, Geneva, Switzerland: WHO; 2016. $\mathrm{p} 1$.

15. O'Connor CA, Patsdaughter CA, Grindel CG, Taviera PF, Steinberg JL. A mobile HIV education and testing program: Bringing services to hard-to-reach populations. AIDS Patient Care STDS. 1998;12(12):931-7.

16. Sharma M, Ying R, Tarr G, Barnabas R. Systematic review and metaanalysis of community and facility-based HIV testing to address linkage to care gaps in sub-Saharan Africa. Nature. 2015;528(7580):S77-85.

17. Government of India. Annual Report 2008-2009, New Delhi, India: National AIDS Control Organization (NACO); 2009. p15.

\section{Tables}

TABLE 1 SOCIO-DEMOGRAPHIC CHARACTERISTICS OF THE STUDY PARTICIPANTS (N=160)

\begin{tabular}{|c|c|c|c|c|c|}
\hline Variables & $\begin{array}{c}\text { Pregnant } \\
\text { women } \\
\begin{array}{c}n=40 \\
n(\%)\end{array}\end{array}$ & $\begin{array}{l}\text { TB patients } \\
\qquad \begin{array}{c}n=40 \\
n(\%)\end{array}\end{array}$ & $\begin{array}{c}n=40 \\
n(\%)\end{array}$ & $\begin{array}{c}\text { Sexual } \\
\text { partners of } \\
\text { PLHIV } \\
n=40 \\
n(\%)\end{array}$ & $\begin{array}{c}N=160 \\
n(\%)\end{array}$ \\
\hline $\begin{array}{l}\text { Age (years) } \\
18-30 \\
31-45 \\
\text { Above } 45\end{array}$ & $\begin{array}{c}38(95) \\
2(5) \\
0\end{array}$ & $\begin{array}{l}23(58) \\
6(15) \\
11(27)\end{array}$ & $\begin{array}{l}25(63) \\
11(27) \\
4(10)\end{array}$ & $\begin{array}{l}15(38) \\
19(47) \\
6(15)\end{array}$ & $\begin{array}{l}101(63) \\
38(24) \\
21(13)\end{array}$ \\
\hline $\begin{array}{l}\text { Gender } \\
\text { Men } \\
\text { Women } \\
\text { Transgender women /Hijra*/ Kinnar* }\end{array}$ & $\begin{array}{c}0 \\
40(100) \\
0\end{array}$ & $\begin{array}{c}20(50) \\
20(50) \\
0\end{array}$ & $\begin{array}{l}20(50) \\
10(25) \\
10(25)\end{array}$ & $\begin{array}{l}18(45) \\
22(55) \\
0\end{array}$ & $\begin{array}{l}58(36) \\
92(57) \\
10(7)\end{array}$ \\
\hline $\begin{array}{l}\text { Educational status } \\
\text { No formal education } \\
1^{\text {st }} \text { to } 12^{\text {th }} \text { grade } \\
\text { Diploma/graduate/postgraduate }\end{array}$ & $\begin{array}{c}9(22) \\
30(75) \\
1(3)\end{array}$ & $\begin{array}{l}9(23) \\
22(54) \\
9(23)\end{array}$ & $\begin{array}{c}2(5) \\
30(75) \\
8(20)\end{array}$ & $\begin{array}{c}3(8) \\
29(72) \\
8(20)\end{array}$ & $\begin{array}{l}23(14) \\
111(70) \\
26(16)\end{array}$ \\
\hline $\begin{array}{l}\text { Residence } \\
\text { Urban } \\
\text { Rural }\end{array}$ & $\begin{array}{c}40(100) \\
0\end{array}$ & $\begin{array}{c}40(100) \\
0\end{array}$ & $\begin{array}{l}30(75) \\
10(25)\end{array}$ & $\begin{array}{l}14(35) \\
26(65)\end{array}$ & $\begin{array}{c}124(76) \\
36(24)\end{array}$ \\
\hline $\begin{array}{l}\text { Monthly family income (INR) } \\
\leq 10,000 \\
11,000-20,000 \\
>20,000\end{array}$ & $\begin{array}{l}32(78) \\
4(11) \\
4(11)\end{array}$ & $\begin{array}{l}27(67) \\
9(23) \\
4(10)\end{array}$ & $\begin{array}{l}27(67) \\
9(23) \\
4(10)\end{array}$ & $\begin{array}{l}31(77) \\
6(15) \\
3(8)\end{array}$ & $\begin{array}{l}117(73) \\
28(18) \\
15(9)\end{array}$ \\
\hline $\begin{array}{l}\text { Marital status } \\
\text { Married } \\
\text { Currently single } \\
\text { Separated/divorced/widowed }\end{array}$ & $\begin{array}{c}39(98) \\
1(3) \\
0\end{array}$ & $\begin{array}{c}22(55) \\
16(40) \\
2(5)\end{array}$ & $\begin{array}{l}14(35) \\
26(65) \\
0\end{array}$ & $\begin{array}{c}39(97) \\
1(3) \\
0\end{array}$ & $\begin{array}{c}44(28) \\
114(71) \\
2(1)\end{array}$ \\
\hline Living arrangements & & & & & \\
\hline
\end{tabular}


INDIAN JOURNAL OF COMMUNITY HEALTH / VOL 32 / ISSUE NO 01 / JAN - MAR 2020

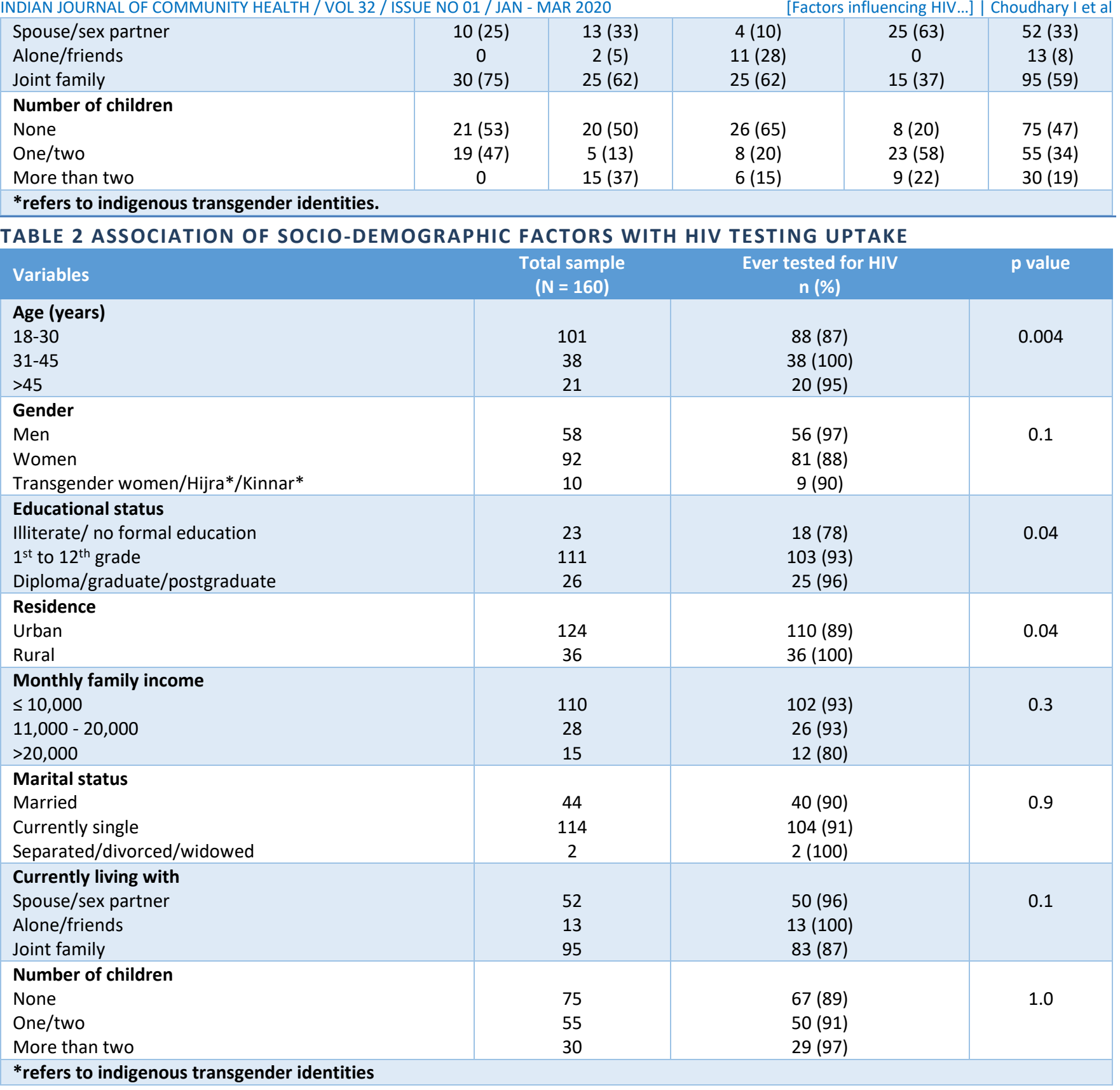

\begin{tabular}{|c|c|c|c|c|}
\hline Variables & $\begin{array}{l}\text { Total sample } \\
(\mathrm{N}=160)\end{array}$ & $\begin{array}{l}\text { Ever tested for HIV } \\
\qquad \begin{array}{c}n=146 \\
n(\%)\end{array}\end{array}$ & $\begin{array}{l}\text { Adjusted Odds Ratio (aOR) } \\
\qquad(95 \% \mathrm{Cl})\end{array}$ & $p$ value \\
\hline $\begin{array}{l}\text { Age } \\
\text { Above } 30 \text { years } \\
18-30 \text { years (Ref.) }\end{array}$ & $\begin{array}{c}59 \\
101\end{array}$ & $\begin{array}{l}58(98) \\
88(87)\end{array}$ & $\begin{array}{c}8.62(0.08-1.25) \\
1\end{array}$ & 0.07 \\
\hline Knowledge about HIV/AIDS score & 160 & $146(91)$ & $1.75(1.22-2.51)$ & 0.002 \\
\hline $\begin{array}{l}\text { Family support } \\
\text { Agree } \\
\text { Disagree (Ref.) }\end{array}$ & $\begin{array}{c}121 \\
39\end{array}$ & $\begin{array}{l}118(98) \\
28(72)\end{array}$ & $\begin{array}{c}8.25(1.92-35.31) \\
1\end{array}$ & 0.004 \\
\hline $\begin{array}{l}\text { Contact with service providers (peer } \\
\text { educator/healthcare provider) Agree } \\
\text { Disagree (Ref.) }\end{array}$ & $\begin{array}{c}142 \\
18\end{array}$ & $\begin{array}{c}132(93) \\
14(78)\end{array}$ & $\begin{array}{c}1.35(0.24-7.48) \\
1\end{array}$ & 0.7 \\
\hline
\end{tabular}


TABLE 4 BARRIERS AND FACILITATORS TO HIV TESTING UPTAKE IDENTIFIED AND CATEGORISED FROM OPEN-ENDED RESPONSES

\begin{tabular}{|c|c|c|}
\hline Levels & Barriers & Facilitators \\
\hline \multirow[t]{3}{*}{ STRUCTURAL/POLICY } & Stringent policy guidelines in HIV testing & $\begin{array}{l}\text { Pro-HIV testing policies (Availability } \\
\text { of the HIV test at the nearby } \\
\text { preferred locations or mobile van } \\
\text { testing and less waiting period) }\end{array}$ \\
\hline & $\begin{array}{l}\text { Insufficient funds for HIV testing programs (leading to shortage of } \\
\text { human resources, perceived low salary packages, along with } \\
\text { reported delays in receiving their salaries) }\end{array}$ & $\begin{array}{l}\text { Government initiatives (Provision of } \\
\text { free of cost tests, incentives, } \\
\text { monetary reimbursements of travel } \\
\text { cost, advertisements and } \\
\text { collaboration with private facilities } \\
\text { to offer free HIV tests) }\end{array}$ \\
\hline & Distrust on HIV testing modalities & $\begin{array}{l}\text { Involvement of non-government } \\
\text { organisations (NGOs) in HIV testing } \\
\text { programs }\end{array}$ \\
\hline \multirow[t]{2}{*}{ SOCIETAL } & Social norms that stigmatise HIV testing & \\
\hline & $\begin{array}{l}\text { Discrimination from society (for example among key populations, the } \\
\text { anticipated fear of rejection from their own community, eviction } \\
\text { from home, social isolation and loss of income from the sex work) }\end{array}$ & \\
\hline \multirow[t]{4}{*}{ HEALTH SYSTEM } & $\begin{array}{l}\text { Inconsiderate administrative procedures for HIV testing (e.g., } \\
\text { unsuitable opening hours [for certain key populations] for HIV testing } \\
\text { services, demand of identity proof, long waiting periods. Need to visit } \\
\text { the facility twice to collect the test result) }\end{array}$ & $\begin{array}{l}\text { Empathetic attitude of healthcare } \\
\text { providers }\end{array}$ \\
\hline & \multirow{2}{*}{$\begin{array}{l}\text { Perceived inefficiency and insensitivity/discrimination of healthcare } \\
\text { providers (i.e., some transgender women at facilities were admitted } \\
\text { in male wards and were made to stand in male waiting lines) }\end{array}$} & $\begin{array}{l}\text { Provision of good counselling at the } \\
\text { hospital }\end{array}$ \\
\hline & & Suggestions from healthcare staff \\
\hline & $\begin{array}{l}\text { Had to pay for HIV test at private facilities/denied test at government } \\
\text { facilities }\end{array}$ & $\begin{array}{l}\text { Knowledge from meetings and } \\
\text { trainings at NGOs) }\end{array}$ \\
\hline \multirow[t]{7}{*}{$\begin{array}{l}\text { PERSONAL AND } \\
\text { INTERPERSONAL }\end{array}$} & Low self-risk perception of HIV & $\begin{array}{l}\text { Knowledge about the disease, } \\
\text { treatment and importance of } \\
\text { testing }\end{array}$ \\
\hline & Lack of awareness about HIV services & $\begin{array}{l}\text { Positive role of peer educators in } \\
\text { promoting HIV testing }\end{array}$ \\
\hline & Financial instability to opt for testing & One's past positive experiences \\
\hline & $\begin{array}{l}\text { Fear of relationship discord if HIV testing revealed (partner's reaction } \\
\text { to one's HIV positive status or fear of disclosure of indulgence with } \\
\text { multiple partners) }\end{array}$ & $\begin{array}{l}\text { HIV testing under Prevention-of- } \\
\text { Parent-to-Child Transmission } \\
\text { (PPTCT) programme }\end{array}$ \\
\hline & Stress after unsafe sex/ risk of getting infected from partner & $\begin{array}{l}\text { Self-motivation to have a healthy } \\
\text { life }\end{array}$ \\
\hline & & Support from family/friends \\
\hline & & $\begin{array}{l}\text { To verify if sexual partner/spouse is } \\
\text { HIV positive, given the positive } \\
\text { status of his/her sexual } \\
\text { partner/spouse }\end{array}$ \\
\hline
\end{tabular}

\begin{tabular}{|l|l|l|l|l|l|}
\hline TABLE 5 NEW HIV TESTING MODALITIES: PREFERRED FACILITIES AND TYPE OF TESTS \\
\hline \hline
\end{tabular}




\section{Figures}

FIGURE 1 BARRIERS TO HIV TESTING UPTAKE AMONG PRIORITY POPULATIONS

Preference of nearby testing location Lack of family support

Fear of being labelled as HIV positive Lack of confidentiality

Fear of being seen at testing centre Concern about loss of wages/travelling cost Treated unfairly by family/friends Harrassment by police Long waiting period Low service at health facilities Treated unfairly by health care staff
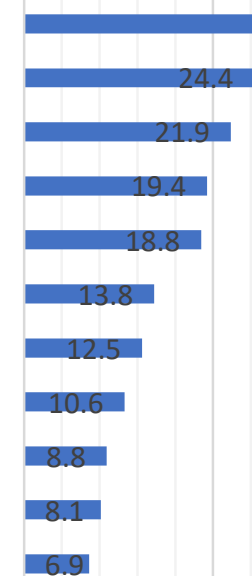

0

20

40

60

80

100

Percentage of study participants

\section{FIGURE 2 FACILITATORS OF HIV TESTING UPTAKE AMONG PRIORITY POPULATIONS}

\section{Contact with service providers \\ Knowing an HIV-positive person \\ Government initiatives}

0

20

40

60

80

100

Percentage of study participants

FIGURE 3 OVERALL BARRIERS AND FACILITATORS TO HIV TESTING UPTAKE

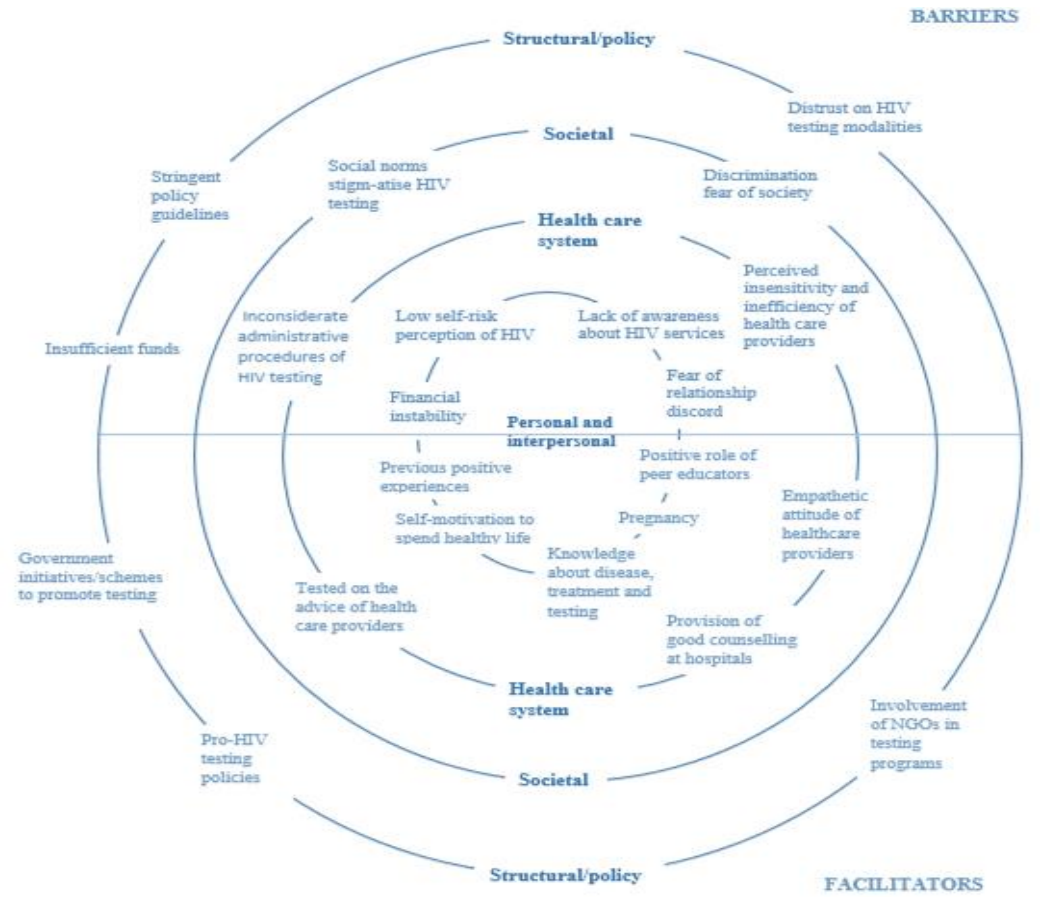

